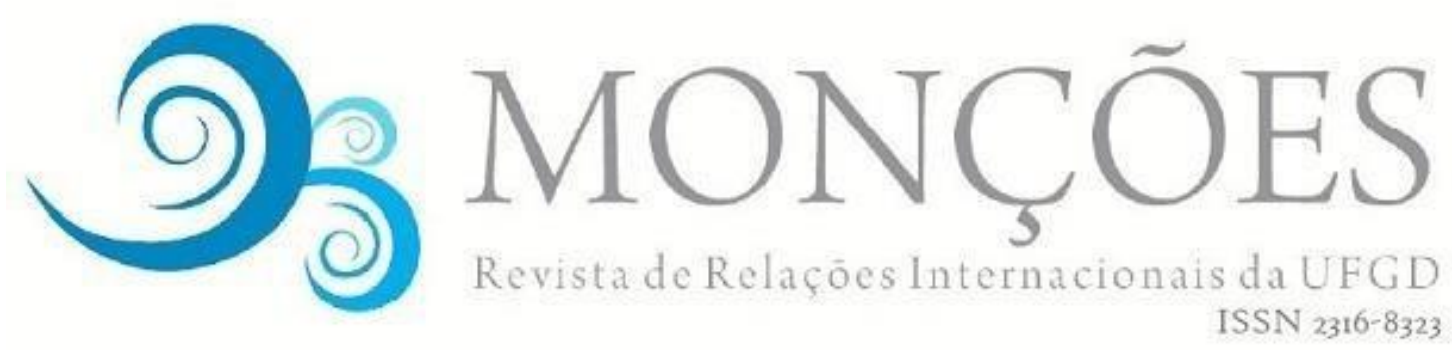

\title{
ENTREVISTA COM EMBAIXADOR JOÃO GOMES CRAVINHO REPRESENTAÇÃO DA UNIÃO EUROPEIA NO BRASIL
}

\section{ENTREVISTADORES}

TOMAZ ESPÓSITO NETO

Doutor em Ciências Sociais pela Pontifícia Universidade Católica de São Paulo, professor de Relações Internacionais da Universidade Federal da Grande

Dourados e Coordenador da Cátedra Jean Monnet (UFGD).

HENRIQUE SARTORI DE ALMEIDA PRADO

Doutor em Ciência Política pela Universidade do Estado do Rio de Janeiro, professor de Relações Internacionais da Universidade Federal da Grande

Dourados e Coordenador Adjunto da Cátedra Jean Monnet (UFGD).

Revista Monções - O senhor poderia falar sobre a sua trajetória acadêmica e profissional e quais são os desafios de ser o representante da delegação aqui no Brasil?

João Gomes Cravinhos - Bom, minha trajetória é uma trajetória inesperada. Não é uma carreira habitual, porque eu tenho umas mudanças que, enfim, foram frutos do acaso, de circunstâncias particulares.

Comecei com uma carreira acadêmica. Fiz um Doutorado em Oxford. Depois, fui para a Universidade de Coimbra. Comecei a lecionar. Fui um dos dois fundadores do curso de Relações Internacionais da Universidade de Coimbra, em 1995. É, nesse contexto, que, ocasionalmente, eu comecei a escrever textos de opinião em jornais. Em 2005, ocorreu uma inflexão inesperada no meu percurso, como professor universitário. Em março de 2005, fui convidado para ir para o governo, como Vice-Ministro, Secretário de Estado de Negócios Estrangeiros e da Cooperação do Governo de Portugal. Fiquei nessa 
circunstância durante 6 anos e tomei muito gosta pela carreira diplomática. Em 2011, a União Europeia criou o Serviço Europeu para a Ação Externa (SEAE). Com a proximidade do fim do governo português, surgiu, de repente, a possibilidade de me candidatar para postos no SEAE.

Eu me candidatei a embaixador da União Europeia na Índia. Eu tinha uma ligação afetiva/pessoal, com a Índia. Quando eu era um jovem idealista, fui para a Î́ndia trabalhar numa organização não governamental. Eu achava que poderia mudar o mundo, e a Índia parecia um bom local para começar a mudar o mundo. O mundo mudou pouco. A Índia muito menos. Eu, no entanto, aprendi muito com essa experiência. Enfim, eu me candidatei e fui selecionado para Embaixador da União Europeia na Î́ndia. Fiquei lá até julho de 2015.

Em 2015, o posto de Embaixador da União Europeia no Brasil vagou. Tendo em vista, a minha experiência anterior na Índia, candidatei-me a este posto no Brasil. Desde então, eu sou o Embaixador da União Europeia no Brasil.

Pode-se dizer que me tornei um diplomata por "acidente". A vida nos traz surpresas. Felizmente essas foram surpresas muito positivas, muito enriquecedoras. As minhas funções aqui se beneficiam bastante as minhas experiências anteriores, da minha vida acadêmica, também da minha vida política no governo. Porque, são experiências que me permitem olhar para este trabalho aqui no Brasil, com outros olhos. Espero que isso se reflita na qualidade do trabalho, obviamente este é o objetivo, foi assim que eu disse nas entrevistas que ia ser, portanto foi assim que fui selecionado.

A delegação da União Europeia representa a Comissão Europeia e o Conselho Europeu. A Comissão Europeia é o "Poder Executivo" da União Europeia, a qual é composta pelas diferentes Direções Gerais. Estas são equivalentes aos Ministérios num país. Por exemplo, temos a Direção Geral de Agricultura e Desenvolvimento Rural, a Direção Geral de Energia, entre outros.

O Conselho Europeu representa o nível mais elevado de cooperação dos 28 Estados-membros da União Europeia. O Tratado de Lisboa, firmado em 2007 e, em vigor desde 2009, reformou as atribuições do Conselho. Por isso, antes da entrada em vigor do Tratado de Lisboa, os meus antecessores no cargo eram chamados de delegados da Comissão Europeia, pois representavam apenas a 
Comissão Europeia. Não representavam os países reunidos do Conselho Europeu.

As minhas cartas credenciais, foram assinadas pelo Presidente da Comissão Europeia, Jean-Claude Juncker e pelo Presidente do Conselho Europeu, o Donald Tusk. Portanto, tenho duas assinaturas nas cartas credenciais, porque eu represento as duas instituições.

A representação tem 60 funcionários no Brasil. Dois terços deles são pagos pelo lado da Comissão Europeia. Outro terço é pago pelo Conselho Europeu. Eu também tenho funcionários especializados nas diferentes áreas, tais como na seção política, na seção econômica, entre outros. Portanto, há um leque alargado de matérias que são tratados aqui, que representam as matérias do nosso relacionamento bilateral da União Europeia no Brasil.

RM - Em 2017, o Tratado de Roma (1957) completou 60 anos. Qual é o balanço que o senhor faz do processo de integração europe u? Quais foram os sucessos, os fracassos? E quais são os desafios a serem enfrentados?

JGC - São imensos, quer dizer, a lista é grande qualquer que seja o tipo dos sucessos, dos fracassos, das dificuldades e das surpresas. Isto é, se nós pensarmos, em março de 1957, quando foram assinados os Tratados de Roma (Tratado das Comunidades Econômicas e o Tratado da EURATOM). Acho que, em 1957, ninguém imaginaria a velocidade da evolução cooperação entre os membros da União Europeia.

O processo de integração é um processo surpreendente. É um processo muito mais profundo, com muito maior impacto do que se imaginava nos anos 50 . Acho que é uma das grandes surpresas da história mundial do século XX. Portanto o primeiro ponto, a escala e o nível de integração foram muito superiores ao imaginado.

Segundo ponto, o processo de integração europeia demonstra que a União Europeia acompanha as necessidades históricas do momento em particular, seja numa fase inicial, seja na expansão suave do mercado único. 
Pouco depois da queda do Muro de Berlim (1989), o Tratado Maastricht (1992) foi necessário para propiciar as condições de uma reintegração política no continente que se daria dentro do projeto Europeu. Os países que, faziam parte do bloco soviético, como Polônia, Hungria, Bulgária, Romênia, entre outros tinham aspirações legítimas para pertencer ao projeto europeu.

$\mathrm{O}$ projeto europeu, para tanto, teve de se refundar completamente. A única solução foi avançar. A União Europeia, muitas vezes, é atravessada por impulsos contraditórios que funcionam dando algum equilibrio, algum ímpeto para a frente, e que é a fórmula do aprofundamento mais alargamento e do aprofundamento com alargamento.

O projeto da União Econômica e Monetária surge nesse momento, exatamente para dar novas dimensões de aprofundamento necessário para equilibrar o alargamento. Pode-se citar, a criação do Euro, a moeda comum da maioria dos países da União Europeia, e o início de um processo de integração no conjunto grande de áreas em todo o território europeu. Esse processo fez com que muitas decisões, a serem tomadas em Bruxelas em vez de nas capitais dos Estadosmembros da União Europeia. Portanto, esse foi um processo que vai até os dias de hoje. $O$ processo entra em uma crise a partir dos seus 50 aos 60 anos de existência, que culmina com o referendo do brexit (2016). Afinal, o brexit, ainda não aconteceu, acontecerá em 2019.

O brexit, no sentido voto do referendo, é par de outros desenvolvimentos no cenário internacional, como por exemplo, a eleição do presidente Trump nos Estados Unidos, que coloca em causa o modelo de globalização no qual a União Europeia tinha sido uma grande defensora. Ademais, a emergência da China e, em menor grau, de outros países como o Brasil e a Índia, colocou uma crise de confiança no projeto europeu.

Essa crise de confiança de algum modo foi superada pela conviç̧ão de que a União Europeia deve, por meio de novas propostas, responder aos desafios vindos de diferentes partes do planeta, tais como: os ventos da concorrência asiática, os ventos das dúvidas sobre da globalização que vem dos EUA, as dúvidas sobre o próprio projeto europeu vindo do Reino Unido, entre outros 
Persiste a consciência profunda que qualquer um dos nossos países é pequeno para os desafios da governança global, mas que em conjunto, quando conseguimos ter muita influência nesse plano internacional.

O histórico que eu faço é o histórico por etapas que passa por surpresas, passa por períodos de grande aceleração e aprofundamentos de integração, um período de dúvidas sobre o projeto e eu penso que essa próxima etapa que começa é uma etapa que vamos verificar nos próximos meses caminhos novos a serem claramente identificarmos. Existe uma convicção comum de que queremos ir por caminhos novos e queremos fazê-los juntos.

Existe também uma metodologia estabelecida para identificação desses caminhos novos, em andamento com o livro branco que coloca uma série de perguntas sobre possíveis caminhos futuros da União Europeia, cinco cenários distintos, seguido da publicação de cinco livros brancos centrais especializados ou sobre Europa social, o que significa como é que nós podemos em conjunto, trabalhar temáticas como juventude, emprego, etc.

Questões como a Europa da defesa, segurança da defesa, que é uma das grandes áreas do futuro da União Europeia, uma área pouco trabalhada até agora, por razões diversas. Muito embora fizesse parte dos primeiros primórdios do projeto europeu, com a Comunidade Europeia da Defesa que foi congelada após a não ratificação pelo Parlamento Francês. A ideia estava lá desde o início, agora está sendo retomada com bastante força.

Uma reflexão sobre União econômica e monetária que, a meu ver, passará por um aprofundamento da governança a nível da governança econômica e monetária com uma melhor co-responsabilização pela elaboração dos orçamentos, pela solução de dívidas, pela partilha de dívidas e também pela elaboração de políticas econômicas em comum. Portanto, vamos entrar em uma nova etapa de aprofundamento. Poderá haver um alargamento mais pontual, mas será o aprofundamento a tônica na minha opinião. Essa é a minha leitura de algo que é orgânico. Algo que está em construção. Digamos que estamos a navegar sem mapa. Nós próprios estamos a marchar hoje em dia, com uma autoconfiança que não existia digamos, a um ou a dois anos atrás. 


\section{RM - O senhor comentou sobre o brexit, como é esse processo de negociação da saída da Grã-Bretanha?}

JGC - Há algumas coisas que nós já sabemos e que estão estabelecidas e há outras dinâmicas penduradas para negociações. Depois de nove meses do resultado do plebiscito, o governo Britânico finalmente apresentou uma carta invocando o artigo 50. Não com o resultado do referendo traumático, mas com esta decisão, o processo das negociações poderá, finalmente, avançar. Até então, vivia-se num período de indefinição.

A partir de março de 2017, temos 24 meses para que o Brexit se conclua. O Brexit terá o processo de negociação em duas etapas. Uma primeira etapa que vai começar depois das eleições no Reino Unido, que é em 8 de junho, portanto, digamos que será fundamentada no mês de junho, uma primeira etapa terá a ver com a negociação dos termos de saída ou seja, os termos do divórcio. Uma segunda etapa, que só poderá começar quando a primeira etapa estiver bem avançada, em que se vai negociar os termos do novo relacionamento com o Reino Unido. É importante esse esclarecimento, é importante que haja clareza nos termos do divórcio antes de ver, antes de poder ver os termos da nova amizade que, esperamos que assim seja, pós divórcio.

Desde 1973, o Reino Unido passou a ser membro da Comunidade Europeia e agora do segmento da União Europeia. O Reino Unido teve um papel importante na criação daquilo que é hoje, a União Europeia, ao mesmo tempo que o Reino Unido é algo completamente diferente do que era a 44 anos atrás, para bem melhor. Portanto, as nossas identidades britânicas e europeias, são identidades e influenciadas umas pelas outras.

O divórcio não é uma simples saída de um sócio deixar de ser membro de um clube, a coisa é bem mais complicada do que isso. As nossas preces e expectativas unânimes, dos 27 , para o berço do Reino Unido, é que a relação pós Brexit, seja uma relação muito próxima, talvez mais próxima do que existe com qualquer outro Estado. Esperamos que o processo de negociação não leve a outro resultado, caso isso ocorra, seria uma enorme pena. Nossa esperança é que a relação continue a ser uma relação muito próxima. Agora, não vai ser a relação que existe atualmente, como Estado-membro, contudo, há regras como, 
por exemplo, do acesso ao mercado único, e, o Reino Unido, tem dado indicação que não está satisfeito com todas essas regras e com a circulação livre de pessoas. Nesse caso, é uma opção soberana, mas não pode estar no mercado único. Haverá, portanto, uma barreira tarifária, haverá barreiras alfandegárias de diferentes tipos, entre o Reino Unido e a União Europeia. Essa negociação sobre o relacionamento pós Brexit, vai ser muito influenciada pela negociação sobre os termos de saída. Então, será um processo difícil e intenso, mas espero que realizado em condições boas e em condições em que os negociadores de ambos os lados mantenham no horizonte grandes objetivos e não apenas na conjuntura imediata.

\section{RM -Terrorismo e refugiados são temas muito polêmicos na atual agenda internacional. Qual é o olhar da União europeia em relação aos refugiados a aos atos de terrorismo?}

JGC - Eu não faço uma ligação entre os dois, repare, nós estamos conversando dois dias depois do terrível atentado em Manchester em que 22 pessoas em um concerto foram mortas e mais 20 pessoas em estado grave no hospital devido a um ataque terrorista. Um ataque terrorista cometido, segundo as informações que nós temos atualmente, por um jovem nascido e criado nessa mesma cidade de Manchester. Não era um refugiado. Igualmente, no ano passado, os ataques que ocorreram em Bruxelas e em Paris, foram realizados por jovens nascidos e criados na França e na Bélgica. Não tem nada a ver com refugiados.

Claro que há políticos e demagogos que aproveitam de um contexto em que as pessoas sentem incertezas e preocupações perfeitamente legitimas porque não entendem este mundo complicado em que há de fato eventos que são extremamente difíceis de enquadrar e que dizem "vejam só, aconteceu essa coisa, vamos fechar as nossas fronteiras". Vai se fechar as fronteiras quando as pessoas já estão dentro das nossas fronteiras? A coisa é muitíssima mais complexa.

No tocante aos refugiados, nós temos vários fatores que eu preciso equacionar em conjunto. Primeiro lugar, temos circunstancias terriveis que levaram fluxos repentinos em grande escala de refugiados, principalmente a guerra da Síria e a 
instabilidade política em outras partes do Oriente Médio, em particular o Iraque. Segundo, temos também situações de grande instabilidade política e precariedade econômica em outros países da nossa vizinhança como é o caso da Líbia. Temos também fluxos de imigrantes econômicos que chegam de outras partes do continente africano e, mesmo da Ásia mais longínqua, como os fluxos do Afeganistão e do Paquistão.

Ora, em 2015, houve uma pressão enorme em relação as fronteiras europeias com a entrada de cerca de um milhão e meio de refugiados, alguns migrantes econômicos, entre outros. Todos em busca de uma vida melhor, o que é perfeitamente razoável e legítimo. A saída encontrada é uma solução temporária, então o problema da globalização e os fluxos migratórios são, em grande parte causada pela globalização e tem acontecido no Mediterrâneo. Daqui 5 ou 10 anos, eu não sei donde vai acontecer. Só sei que haverá, pode ser em outra parte do planeta, provavelmente será em outra parte do planeta!

Agora, o que temos obrigação de saber fazer é: primeiro, distinguir entre refugiados e imigrantes econômicos porque as nossas obrigações são distintas em cada um dos casos. Temos que saber apoiar e integrar aqueles que entram na Europa, temos que saber distribui-los pelo território europeu e isso implica conversas complicadas entre os países europeus. No meu entender, não é aceitável que alguns países da união europeia, com os valores que união europeia tem, digam simplesmente "nós não vamos assumir nenhuma parte da nossa responsabilidade em relação a outras pessoas que vem de outras partes do planeta". Também, deve-se dizer de passagem que o próprio futuro da própria união europeia, dos países, depende de conseguirmos rejuvenescer nossa população e, qualquer economista ou demógrafo sério, saberá dizer que a Europa precisa de migrantes de outras partes do mundo.

Contudo, o contexto atual é de incertezas sobre um mundo em rápida mutação. Produz-se não só incertezas, como inseguranças em pessoas. Isto produz um "caos" em que proliferam e progridem alguns políticos mais demagógicos.

Estamos em maio de 2017 e eu creio que já passamos pelo pior em matéria de tentações demagógicas. Naturalmente, isso tem um impacto sobre a forma que os políticos lidam com a problemática das fronteiras de quem está dentro, de quem está fora e como é que nos absorvemos as pessoas vindas de outras 
partes do mundo. Mas, dito isso, acredito que hoje há uma convicção a qual não existia há seis meses atrás. Existe a necessidade de combatermos esta analogia entre terrorismo e refugiados. Para tanto, é necessário respondermos com seriedade, com políticas claras que apoiam a inserção refugiados. No entanto, ao mesmo tempo, também é preciso dizer: a Europa não tem lugar pra todo mundo, não é possível absorver na Europa todos aqueles que gostariam de viver na Europa. Mas, alguns que atualmente lá vivem, é certeza que sim.

\section{RM - Qual é a importância do Comitê de Regiões e da sociedade civil na formação das políticas da União Europeia?}

JGC - Bom, as duas temáticas são distintas. O Comitê de Regiões é importante e é significativo para nós porque lá estão representadas 350 entidades, que podem ser municípios, que podem ser aglomerações regionais, como, as províncias espanholas, as quais tem também uma grande autonomia. Há todo o conjunto de entidades subnacionais, mas que são promoventes de governança, cuja a voz tem que ser ouvida na elaboração de políticas. Muitas vezes, são essas entidades, mais até que os governos nacionais, que tem a responsabilidade de pôr em prática as políticas que são pensadas em Bruxelas. Então, a voz dessas entidades é absolutamente fundamental.

De forma alguma não estou a falar por exemplo, da política externa da União Europeia, na política de defesa da União Europeia, que são pensados a nível dos Estados-membros e das capitais, mas, em termos de quase todas as outras políticas, temos obrigação de ouvir as atividades que estão mais próximas dos cidadãos e assim, representam a voz direta dos cidadãos.

No caso das alterações climáticas, por exemplo, é, relativamente, fácil um país dizer "Sim senhor, nós assumimos uma meta que é de reduzir, não sei quantos por cento, as emissões de carbono até...", mas quem é que vai fazer essa redução? Não é o Primeiro-Ministro sentar no seu gabinete. É em nível local, é o Presidente do município e em muitas vezes essas entidades que estão no comitê de organização. Então, para nossa realidade contemporânea, o Comitê das Regiões é absolutamente fundamental. 
Em relação a sociedade civil, nossa convicção é que a democracia precisa ir se reinventando constantemente. Quando trabalhada no plano europeu, precisa absolutamente de ter é uma sociedade civil muito ativa, porque nós estamos habituados a exercer o nosso mais básico direito de cidadania, que é o direito ao voto. Estamos habituados a exercê-lo pensando no enquadramento nacional, ou as vezes, no enquadramento local, também nas eleições locais.

No projeto europeu, nós precisamos, não apenas do Parlamento Europeu - em que todos os eleitores europeus podem votar -, mas devemos pensar no projeto democrático. Temos de pensá-lo por meio do envolvimento ativo em todos os momentos de elaboração de políticas públicas.

Os atores representam os diversos interesses e organizam, assim, as associações da sociedade civil, quer seja associações empresariais, associações de classes e sindicatos, associações de interesses particulares, de lobbies de diferentes tipos. Portanto, a sociedade civil já é um agente muito importante.

O Tratado de Lisboa estabelece as políticas públicas devem ser elaboradas por via da consulta pública, com envolvimento de todos os interessados e de forma transparente. A transparência é muito importante. Não existe transparência na elaboração de políticas públicas, se as associações da sociedade civil nem sabem como e quando intervir. Então, essa transparência é uma obrigação e está refletida na forma de fazer a elaboração das políticas públicas, e permite o envolvimento das associações na sociedade civil. Eu creio que, hoje já é muito importante e no futuro, ainda mais.

A democracia europeia, no contexto do mundo cada vez mais complexo, precisa ter o envolvimento dos cidadãos de uma maneira direta, que não seja apenas o seu exercício ao voto, a cada dois ou três anos.

\section{RM - Qual é a sua relação com o Parlamento Europeu?}

JGC - O Parlamento Europeu é uma das instituições fundamentais da União Europeia. Nós temos uma relação indireta com o Parlamento.

Alguns documentos e relatórios sobre a situação política e econômica, por exemplo, são encaminhados ao Parlamento. De vez em quando, grupos de 
parlamentares vêm ao Brasil. Em caso de missão oficial, ajudamos na elaboração do programa e damos todo o apoio possível.

Por exemplo, um grupo parlamentar fez, recentemente, uma visita ao Mato Grosso e ao Mato Grosso do Sul, para observar a situação dos povos indígenas. Nós oferecemos um apoio puramente institucional. Não nos compete é, emitir juízos sobre se é boa ideia, se é má ideia e se as conclusões do relatório estão totalmente erradas. Esta é uma matéria de soberania estrita do Parlamento Europeu.

Oferecemos o apoio institucional, logístico, entre outros. A representação, no entanto, não serve ao Parlamento Europeu da mesma maneira que servimos as outras instituições, como o Conselho e a Comissão.

RM - Em 2017, a parceria estratégica Brasil e União Europeia fez dez anos. O senhor poderia fazer um balanço dos dez anos de parceria estratégica?

JGC - O conceito de parceria estratégica é um conceito fluído, isto é, primeiro inventou-se o termo e depois procurou dar algum conteúdo e sentido ao termo. Estamos a falar da primeira metade dos anos 2000, quando a União Europeia procurou identificar um conjunto de relacionamentos prioritários que pretendia ter. Um conjunto que não iria para além de dez países. Nas Américas são quatro países: Estados Unidos, Canadá, México e Brasil. Os outros parceiros estratégicos são: China, Japão, Índia, Coreia, Rússia e Ucrânia. Destas, vamos colocar de lado a Rússia, que está congelada, neste momento, por razões conhecidas. A Ucrânia é um país vizinho. A natureza estratégica da nossa relação com a Ucrânia tem a ver com o fato desta ser diretamente vizinha da Rússia.

As outras parcerias funcionam, de forma diferente e com intensidade variável. Existe a ideia de que são relações em que, juntos, a União Europeia e o parceiro estratégico, podem fazer a diferença em termos de governança global. Podem fazer a diferença, um para o outro. 
Depois, surgiram muitos outros candidatos e/ou muitos defensores de se alargar as parcerias estratégicas para o país $A, B$ ou $C$. No entanto, havia o risco do conceito perder significado, quando passa a ser chamado de estratégico.

A nossa relação com a União Europeia e Brasil é uma relação que pode ter um impacto significativo no desenvolvimento do Brasil e no desenvolvimento da União Europeia. Portanto, é preciso uma certa escala em matérias da governança global. Eu vou dar três exemplos sobre a relevância e o impacto da relação entre União Europeia e o Brasil que são desconhecidos pelo grande público, mas os especialistas conhecem bem.

No fim de 2014, a Organização Mundial do Comércio (OMC) estava em meio à crise grave por não ter conseguido, em quase 20 anos, apresentar os resultados. A União Europeia e o Brasil foram decisivos. Juntaram esforços e trabalharam, cada um na sua esfera, com estreita coordenação para produzir um sucesso ministerial, de Nairóbi, que deu nova vida a Organização Mundial de Comércio. Os representantes brasileiros, em especial o embaixador Marcos Galvão e os embaixadores europeus conseguiram que uma instituição fundamental de arquitetura multilateral ganhasse um novo fogo de vida.

Outro momento crucial foi no Fórum Mundial da Internet, em novembro de 2015, na cidade de João Pessoa. Naquele período, houve um movimento forte, por parte de outros países, nomeadamente, a Rússia, a China, o Irã, a Arábia Saudita, entre outros, no sentido de criar uma internet intergovernamental. Uma internet em que os Estados-membros, representando seus governos, teriam capacidades de veto sobre o funcionamento da rede. Na prática, seria o caminho para o fim da internet livre e a criação de uma internet controlada.

O Brasil, que tinha recentemente aprovado o seu marco legal sobre a internet, foi muitíssimo importante naquele momento. O Brasil e a União Europeia trabalharam juntos para derrotar essa linha. Hoje em dia, ela está derrotada. A União Europeia e o Brasil fizeram a diferença para que a internet seja livre e que múltiplas vozes se envolvam na governação global. Portanto, a União Europeia e Brasil fizeram um serviço importante para o mundo.

Terceiro momento, foi na Convenção do Clima, em Paris. Certamente, União Europeia e Brasil não foram seguramente os únicos protagonistas, mas 
trabalharam juntos, cada uma a sua maneira, com base no diálogo e de forma muito próxima para produzir o resultado que foi o Acordo de Paris.

Sem a parceria entre a União Europeia e o Brasil, o Acordo de Paris seria mais difícil de atingir e seria um acordo mais fraco.

Portanto, esses são três exemplos claros sobre a importância da relação entre União Europeia e Brasil e como ambos atores fizeram a diferença, em termos estratégicos, para o mundo. Agora, isso não acontece todos os dias. Felizmente, o mundo não tem esse tipo de crise todos os dias.

No tocante ao relacionamento bilateral da União Europeia e Brasil, minha análise é menos positiva do que aquela que eu faço quanto ao balanço do que fizemos ao mundo. Em parte, pois, a União Europeia estava muito focada para a gestão da sua crise econômico-financeira e política. Depois, o Brasil entrou numa fase de grandes dificuldades econômicas, seguidas de crise política, da qual, ainda não saiu plenamente. Dito isso, o relacionamento tem sido menos intenso do que gostaríamos. Faz parte do processo democrático normal. Somos uma democracia. Na minha perspectiva, teremos um tipo e uma nova velocidade no relacionamento União Europeia e Brasil daqui por um ano ou dois anos.

\section{RM - Como estão as negociações entre a União Europeia e o MERCOSUL?}

JGC - Estão muito bem, por várias razões. Em primeiro lugar, porque existe uma convicção política muito forte de ambos os lados. Nós estamos com uma fantástica janela de oportunidades. Temos de aproveitar porque, se não conseguirmos fazer, vai haver um grande descrédito, não só para a União Europeia e para o MERCOSUL, como para a própria ideia de que conseguimos fazer um acordo. Afinal, as negociações se iniciaram em 1999. Se nós não aproveitarmos esse momento, haverá muito desgaste.

Para conseguimos demostrar aos nossos cidadãos que podemos conseguir ter uma globalização domesticada. Uma globalização que funcione a favor dos nossos povos, e que não tenha nada a ver com a livre ventania que vem de outra parte do planeta, a qual não podemos controlar.

Demonstrar que aproveitamos as oportunidades da globalização, num sentido que é benéfico, para os dois lados e que dá repercussões diretas para o bem- 
estar dos nossos cidadãos. Portanto, esse conjunto de fatores, de natureza conjuntural e filosófica, me levam a acreditar que o estamos em um momento muito propício.

Em correspondência a dinâmica de trabalho, temos um ritmo muito intenso desde o Carnaval de 2017.

Acredito que poderemos produzir um resultado que nós queremos até o final do ano. Isso pode significar muito. Pode significar um incremento muito grande no fluxo de comércio entre a União Europeia e o MERCOSUL, dependendo naturalmente do acordo específico alcançado. Já somos o maior parceiro do Brasil e do MERCOSUL, e, um lugar que foi consolidado em 2016, por comparação com 2015. Acredito que isso possa levar a um incremento bastante grande porque o nosso comércio é muito equilibrado. Neste último ano, produziu um déficit para o lado europeu, mas, nos três anos anteriores, tinha produzido um déficit para o lado brasileiro. O fluxo é, muito qualitativamente equilibrado também. Não é só matérias-primas para um lado e produtos manufaturados para o outro, como acontece com outros parceiros econômicos do Brasil. É uma relação em que vão nos dois sentidos, produtos de diferentes tipos. Há uma grande complementariedade entre as economias, de todas as condições, para fazermos disto um sucesso. Eu acredito que isso vá acontecer.

\section{RM - Além da questão da agricultura, quais outros temas são temas que precisam ser superados?}

JGC - Isso faz parte da negociação. A agricultura é nos dois sentidos. Temos uma agroindústria muito competitiva. Do lado do MERCOSUL, particularmente do Brasilé a mais competitiva do mundo. Temos muitos produtos agrícolas muito competitivos, como azeite, queijo, produtos laticínios, as carnes defumadas, os vinhos, entre outros que também procuram acesso ao mercado do MERCOSUL. Os produtos manufaturados também vão nos dois sentidos. Para nós, é fundamental que o acordo contemple também serviços e compras públicas. Tem de haver uma abertura para o bem do próprio cidadão brasileiro ou dos países do MERCOSUL. Há um outro tipo de possibilidade para as compras públicos, e 
inclusive até o acesso das empresas europeias, empresas brasileiras e do MERCOSUL aos mercados europeus.

Transparência tem que fazer parte disso. O capítulo sobre transparência está em negociação. Esse é um tema de muitíssima importância porque todos têm a consciência que, concorrência livre leal requer também uma certa transparência sobre como que essa concorrência se processa. Isso também é saudável para os dois lados.

Então, temos muito trabalho pela frente. As negociações ainda não estão concluídas. Existe muita boa vontade. Há um acordo total sobre o que tem que estar em cada capítulo, em todos os capítulos há um texto comum. Em alguns casos, o texto tem parênteses porque ainda não há concordância sobre a fraseologia. Pelo menos, temos uma base comum. Não é o caso do início do ano, quando muitos capítulos tinham dois textos. Agora só temos um texto, mas com alguns parênteses. Há muito trabalho pela frente, mas tem muita boa vontade e convicção para podermos chegar ao entendimento.

\section{RM - Última pergunta, qual é a sua mensagem para a juventude?}

JCG - A mensagem que eu tenho para a juventude é a seguinte: é muito interessante para mim vir ao Brasil. Eu vejo aqui muitos dos elementos das matrizes europeias, enriquecidos por uma experiência diferente. Uma experiência das Américas. Uma experiência de um país jovem. Uma experiência também que vai do fato da população do Brasil ter outras origens que não europeias. Eu acho que o Brasil tem imenso a ganhar, não em regressar as suas origens, mas em aproveitar as riquezas que vem das suas origens europeias. Nós, do lado europeu, temos a ganhar em conhecer melhor o Brasil. Se concretizar, o acordo entre a União Europeia e o Mercosul não vai apenas incrementar o comércio, vai aumentar a integração entre os nossos povos. Aumentará o investimento nos dois sentidos. Enriquecerá o fluxo de mobilidade entre estudantes, acadêmicos, profissionais, entre outros. Nesse sentido, eu sou um otimista sobre aquilo de cada um pode trazer para o desenvolvimento do outro. Sou um otimista e não vejo grandes entraves. Então, não aproveitar as possibilidades de cada um traz é de fato desperdiçar uma oportunidade. 


\section{RM - Muito Obrigado}

JCG - Muito obrigado. Foi um prazer.

Entrevista conduzida durante o mês de maio de 2017. 